\section{Colominic Acid, a Substance of Bacterial Origin related to Sialic Acid}

Some years ago, it was found that a mucoprotein derived from submaxillary mucin contained an acidic component which was termed sialic acid ${ }^{1}$. More recently, it has been shown that other mucoproteins of mammalian origin contain substances closely related to sialic acid; among these are neuraminic ${ }^{2}$, gynaminic ${ }^{3}$ and lactaminic ${ }^{4}$ acids. Despite intensive chemical investigations, the structure of these various substances has not yet been fully elucidated.

During an investigation on the nature of colicine $K$, an antibacterial agent elaborated by a strain of Escherichia coli known as $K-235^{5}$, a substanee was encountered in the culture medium which had properties similar in many respects to those of sialic acid. This substance has been termed colominic acid.

Crude colicine and colominic acid may be precipitated from a culture medium in which Escherichia coli $K-235$ has been grown, by adding ethanol at $0^{\circ} \mathrm{C}$. (75 per cent) $)^{6}$ to the concentrated and dialysed solution. Following dialysis, the two substances can be separated by precipitating the colicine at $p \mathrm{H} \quad 5 \cdot 8$ with ammonium sulphate (85 per cent). Colominic acid is isolated from the supernatant, after dialysis, by freeze-drying (yield : 1 gm. from 151 . of culture medium).

Colominic acid is obtained as a snow-white amorphous powder. It is devoid of serological activity and is homogeneous when examined by electrophoresis. It gives only feeble anthrone and biuret tests, and tests for hexosamines, pentoses, and hexuronic acids are negative. Colominic acid dialyses very slowly through 'Cellophane', and an aqueous solution of the free acid has a $p \mathrm{H}$ of $3 \cdot 7$. Upon heating with dilute mineral acid, colominic acid rapidly forms humin. When heated with Ehrlich's reagent, it gives a red colour, and a reddish-purple colour is formed when the substance is heated with Bial's reagent. Colominic acid itself does not reduce Benedict's solution, but after autoclaving an aqueous solution, reducing substances are liberated.

Colominic acid has the following analysis: C, $46.80 ; \mathrm{H}, 5 \cdot 82 ; \mathrm{N}, 4.54 ; \mathrm{CH}_{3} \mathrm{CO}, 15 \cdot 10$. It has an optical rotation in water of $[\alpha]_{D}^{200}=-50 \cdot 5^{\circ}$. Methoxyl groups, sulphur and phosphorus are absent. The neutral equivalent is 326 . From the analytical data the formula $\left[\mathrm{C}_{12} \mathrm{H}_{18} \mathrm{NO}_{8-8}\right]_{n}$ would appear to represent most closely the polymeric form of colominic acid. Each unit is believed to contain one acetyl and one carboxyl group.

Although colominic acid possesses properties which relate it to sialic acid, it shows differences as well. The absorption maximum of the red colour produced by colominic acid in the Ehrlich test lies at $530 \mathrm{~m} \mu$ whereas that of sialic acid is at $565 \mathrm{~m} \mu$. The absorption coefficient of the two substances at $530 \mathrm{~m} \mu$ is identical; at $565 \mathrm{~m} \mu$, however, that of colominic acid is slightly lower. Sialic acid gives a positive Bial reaction when tested under conditions described by Werner and Odin 7 , but colominic acid does not. Finally, it should be said that colominic acid is an amorphous macromolecular material whereas sialic acid is a crystalline substance.

The fact that sialic and colominic acids show closely related absorption spectra in the infra-red region also attests to similarities in their structures (we are greatly indebted to Dr. Herbert Jaffe of this Institute for the spectral measurements). It will be seen from

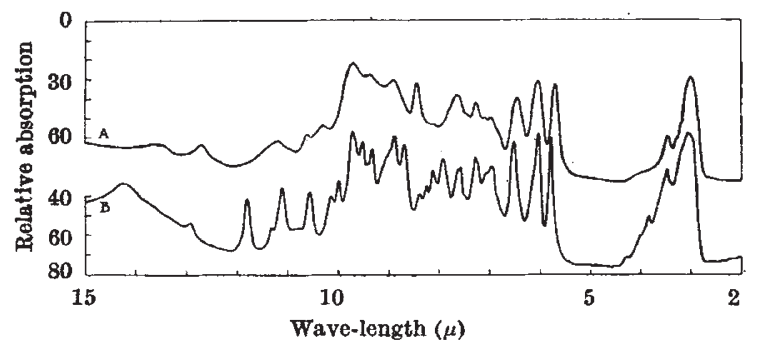

Fig. 1. Infra-red adsorption spectra of colominic acid $(A)$ and of sialic acid $(B)$. Measurements were made using $1-\mathrm{mgm}$. samp

Fig. 1 that the spectral bands of the two substances show excellent conformity at the shorter wavelengths. At longer wave-lengths, however, this is not the case. Because of the amorphous and polymeric nature of colominic acid, broadening of its spectrum in this region is to be expected.

In sum, a substance of relatively high molecular weight is elaborated by the micro-organism Escherichia coli $K-235$, which bears a close relationship to sialic acid. 'This substance has been termed colominic acid. Its exact biochemical function is at present unknown, but it is hoped that future work will elucidate this point.

\section{GUY T. BARRY \\ WAITHER F. GOEBEL}

Rockefeller Institute for Medical Research, New York.

Blix, G., Kossel Z. physiol. Chem., 240, 43 (1936).

Klenk, E., Kossel Z. physiol. Chem., 268, 50 (1941).

Zilliken, F., Braun, G. A., and György, P., Arch. Biochem. Biophys., 54, 564 (1955).

4 Kuhn, R., and Brossmer, R., Chem. Ber., 87, 123 (1954).

s Fredericq, P., Rev. Belge Pathol. Med. Exp., 19, Supp. 4 (1948).

- Goebel, W. F., Barry, G. T., Jesaitis, M. A., and Miller, E. M., Nature, 176, 700 (1955). Goebel, W. F., Barry, G. T., and Shedlovsky, T., J. Exp. Med., 108, 577 (1956).

'Werner, I., and Odin, L., Acta Soc. Med. Opsala, Sweden, 57, 230 (1952).

\section{Vertebrate and Invertebrate Tropomyosins}

As a first step toward generalizing the relationship between tropomyosin, actin and myosin found for rabbit skeletel muscle ${ }^{1}$, we have prepared and exam. ined tropomyosins from the different types of mammalian muscle (cardiac, uterine and smooth), from lower classes within the vertebrate phylum (amphib. ian, fish and cyclostome) and from representatives of different invertebrate phyla (arthropod, molluse, echinoderm, annelid and nemertian).

Most of these proteins crystallize in plates or in various types of needles. All have sedimentation constants falling along the same line and extrapolating to an $S_{20,20(c=0)}$ of about $3 \cdot 0$ (Fig. 1).

On the basis of amino-acid composition, the tropomyosin of mammalian striated muscle can be distinguished from the tropomyosins of smooth muscle, of uterus and of the lower vertebrates; the differences are small and limited to about seven of the amino-acids. In the composition of the invertebrate tropomyosins, the differences are much larger and affect nearly all the amino-acids; nevertheless, there is adherence to the general tropomyosin pattern of, for example, high glutamic acid content (160$200 / 10^{5} \mathrm{gm}$.), low proline content $\left(1 \cdot 6-10 / 10^{5} \mathrm{gm}\right.$.) and histidine content $\left(3 \cdot 4-13 / 10^{5} \mathrm{gm}.\right)$.

Although within the several phyla studied, practically every amino-acid seems susceptible to 